\title{
Teaching Strategies for Enhancing Peer Interaction among Diverse Learners
}

\author{
Helena Hing Wa Sit \\ Correspondence: Helena Hing Wa Sit, Macquarie University, Sydney, Australia. Tel: 61-2-9850-7967. E-mail: \\ Helena.sit@mq.edu.au
}

Received: September 27, 2012 Accepted: October 16, 2012 Online Published: November 28, 2012

doi:10.5539/hes.v2n4p31

URL: http://dx.doi.org/10.5539/hes.v2n4p31

\begin{abstract}
Hong Kong's universities have been attracting non-local students to diversify the overall student mix and enhance internationalism in higher education. Mainland Chinese students have become the largest non-local student source in this Western-style higher education sector. The diversity of student body together with the promotion of multicultural experience has created major concerns about provision of high quality learning and teaching. Studies show there have been potential peer interaction obstacles between local and mainland students due to different social, cultural and educational backgrounds. However, research on the role of teachers in facilitating peer interaction is limited. This paper reports an investigation on how teaching strategies used in the English Department had an impact on enhancing peer interactions in the university classroom context. Classroom observation containing textual descriptions and numeric interpretations was used. Solutions were recommended to improve the multicultural learning environment in Hong Kong and other universities with diverse student cohorts.
\end{abstract}

Keywords: higher education, pedagogy and curriculum, teaching strategies, English studies, cultural diversity, classroom interaction

\section{Introduction}

The increasing growth of economic globalization has been fastening pace of internationalisation of higher education in Hong Kong that aims to become a regional education hub with the international reputation. In the decade since the handover, Hong Kong's universities have increasingly been attracting non-local students to diversify the overall student mix and enhance internationalism of higher education. As a result of growth of internationalisation and localisation, Mainland Chinese students, attracted by the strengths of the Hong Kong higher education sector such as good worldwide academic rakings, a place where the East meets the West, multicultural and multilingual environment and geographic proximity, have become the majority of non-local component in Hong Kong higher education (University Grants Committee-UGC, 2010). In spite of a rapid social change and close connections to Chinese education system, Hong Kong still more or less maintains a British-style higher education which is reflected by the fact that English is used as the medium of instruction and Western-oriented pedagogy is widely adopted. The diversity of student body together with the promotion of multicultural experience for students for both local and non-local students has created one of the major concerns about provision of high quality teaching and learning in Hong Kong's universities. Therefore these students are of interests to many academics who are facing new challenges of learning and teaching in Hong Kong.

In Western educational settings, Chinese background students' overseas study experiences are examined by many studies (e.g., Hsieh, 2012; Su, 2006; Zhang, 2005). However, seldom do studies identify the differences in learning between Chinese-background students of various nationalities and ethnicities (Smith, 2001; Thao \& Li, 2006). For example, Snider (2005) viewed Chinese-backgrounds students from Mainland China, Kong Kong, Singapore, Malaysia and Indonesia as a big homogenous group without considering their different social, cultural and educational backgrounds. Literature supports students' cultural assumptions and prior educational experience can impact their conceptions of learning and expectations of their lectures in the host academic institutional context (Sit \& Chen, 2010). It is essential for teachers to understand their learner behaviors, attitudes to learning and interaction pattern so as to facilitate classroom interactions.

In Hong Kong's Western-Style higher education, research of learning and teaching are concerned with either Hong Kong Chinese background students or Mainland Chinese background students, but not a comparison of the 
two sub-cultural groups. These studies have challenged the stereotypes of the ways Hong Kong students engage in the process of learning (Dahlin \& Watkins, 2000; Watkins \& Biggs, 2001). Some studies have explored the adaptations of Mainland Chinese students to the universities in Hong Kong, including their acculturation experience (Zeng, 2006) and shift English learning strategy use (Gao, 2007b). However, only a few have paid attention to the both groups of Hong Kong Chinese and Mainland Chinese students in terms of interaction (Lam, 2006; Sit \& Chen, 2010).

When Lam (2006) explored the adjustment experience of a group of Mainland undergraduate students at a university in Hong Kong, she found evidence that the adjustment of the host group to the Mainland fellow students was as difficult as that of the sojourning group. She examined the reciprocal adjustment between the host group of Hong Kong students and sojourning group of Mainland Chinese students by analysing their different social and cultural perspectives and perceptions of learning. Nevertheless, there are at least two questions remained for a further investigation although her study has revealed that positive peer interaction should be better enhanced between the local and Mainland students:

First, are English language background and language proficiency contributing problems with interaction? The linguistic facility of the host group and the sojourning group need further exploration. The previous secondary education they received under the language policies put forward by respective governments should be taken into consideration. Their levels of proficiency in both English and Chinese might be analysed in relation to communication and classroom interaction. Second, Lam placed herself with both groups of students to observe the interactional behaviors, but she did not examine the role of a teacher who should facilitate interaction. In addition to cultural and linguistic influences on learning, pedagogy is another significant contributor to student interaction. If appropriate, effective teaching activities had been used, the difficulties in interaction revealed by Lam might have been reduced. An effective teacher should provide solutions to overcome the difficulties in order to promote student learning and classroom interaction.

To conduct the project in a manageable way, this study attempted to examine the role of a teacher in enhancing positive interaction between Mainland Chinese and Hong Kong students because the full-time Mainlanders have comprised of the bulk of the non-local recruits (UGC, 2010). Diverse learners should be encouraged to engage in teaching activates that are more likely to lead to quality learning and cross-cultural communication. Effective teaching strategies should accommodate diverse learners and enhance classroom interaction (Killen, 2007; Westwood, 2008). Although language teaching methods for Special Purposes have long been discussed (Kumaravadivelu, 2005; Richards \& Rogers, 2001), there is limited research on discipline-based study in English to date (Sit \& Chen, 2010). This study sought to contribute to literature on inclusive teaching strategies in English studies.

\section{Research Methods}

Classroom observation, one of the salient techniques of an ethnography approach, was used to capture a holistic overview of the context from the inside through observing learning and teaching in the contemporary context of Hong Kong's universities and to examine how Mainland Chinese and local Hong Kong students behaved and interacted with each other when engaging in class activities. Observation enabled the researcher to obtain a first-hand experience with participants, record anything that occurs, notice any unusual aspects, and explore topics that participants may feel uncomfortable discussing (Creswell, 2007). By stepping into everyday life of individuals or groups, the researcher took field notes which described the situation and events in an unstructured or semi-structured way. Observations could provide the researcher with a general picture of how teachers taught, how students responded, and to what extent students interacted with each other. Both teachers' and students' behaviours could be witnessed. Since the researcher is trilingual (she speaks Chinese Mandarin, Cantonese and English) and bicultural (she has lived in Hong Kong and on the Mainland), an ethnographical investigation could take advantage of the researcher's linguistic ability and cultural awareness.

This study was conducted at the English department, the Hong Kong Institute of Education (HKIEd), the only UGC-funded institution dedicated solely to teacher education in Hong Kong. It has witnessed a substantial increase of Mainland students enrolled in the program of pre-service teacher training of English in the institution and accounted for approximately $98 \%$ of the total non-local student population in the academic year of 2010/11 (UGC, 2011). Currently, there are a large number of Hong Kong and Mainland Chinese students studying in the institute. The focus placed exclusively at English department is also an advantage of avoiding too much discrepancy between the two groups of students' English proficiency.

The observation lasted five weeks covering the teaching programs listed in the class timetable. In total eleven classes by seven teachers were visited. The lessons were normally two to three hours of lectures and tutorials for 
the students from Year One to Year Three. An observational protocol for recording on-site field notes was used. The observation manual addressed two content areas based on the teaching activities: background information and classroom interaction including teacher-student and student-student interactions. After each observation, the recorded notes were sent to teachers to check whether the class activities and student engagement were accurate so that validity could be assured and subjectivity could be at least lessened if not prevented.

\section{Study Results}

The observations were conducted in a purposeful and careful manner. Teaching activities and peer interactions were recorded in accordance with the timeline of the lesson. Table 1 provides a summary of the number of lessons and the observed courses in English studies:

Table 1. Summary of Lesson Observations and Courses at HKIEd

\begin{tabular}{|c|c|c|c|c|}
\hline No. of Teachers & No. of lessons & Courses & Course Type & Grade Level \\
\hline T’1 & 2 & Literary Studies & Tutorial & Yr. $1 \& 2$ \\
\hline$T^{\prime} 2$ & 2 & $\begin{array}{l}\text { Advanced English Proficiency through the } \\
\text { Media \& Developing Oracy }\end{array}$ & Lecture-tutorial session & $\begin{array}{l}\text { Yr } 1 \text { in-service } \\
\text { English teachers }\end{array}$ \\
\hline$T^{\prime} 3$ & 2 & Adolescent Literature in the ESL Classroom & Lecture & Yr. 2 \\
\hline$T^{\prime} 4$ & 2 & ELT curriculum & Tutorial & Yr. 2 \\
\hline $\mathrm{T}^{\prime} 5$ & 1 & $\begin{array}{l}\text { Secondary ELT Methods: Developing Oracy } \\
\text { Skills }\end{array}$ & Lecture-tutorial session & Yr. 3 \\
\hline$T^{\prime} 6$ & 1 & $\begin{array}{l}\text { Psycholinguistics and Second Language } \\
\text { Acquisition }\end{array}$ & Tutorial & Yr. 2 \\
\hline$T^{\prime} 7$ & 1 & Drama Workshop & Lecture-tutorial session & Yr. 2 \\
\hline
\end{tabular}

Courses at HKIEd typically involved a combination of lectures and tutorials. The observed language education of undergraduate programs included modules such as literacy development (e.g., L2 literacy and adolescent literature), language curriculum (e.g., ELT curriculum and syllabus design and management), spoken interaction (e.g., learning and teaching of oral language skills in the L2), psycholinguistics (SLA and language classroom interaction), and drama (e.g., drama workshop). After examining the observation notes, at least two main categories of findings emerged: student engagement in different teaching activities and classroom interaction including teacher-student and peer-peer interactions. The following section analyses data gathered from observations.

\subsection{Student Engagement in Teaching Activities}

The observation scores presented in Table 2 indicate the extent of student engagement during teaching activities that were identified and clarified by the lecturers afterwards based on Killen's (2007) taxonomy of teaching practices. The scores were calculated based on the five-point rating scale from 1 (no engagement) to 5 (very high engagement). It also provides means and standard deviation for student engagement data.

Table 2. Means and Standard Deviation for Student Engagement during Teaching Activities

\begin{tabular}{ccc}
\hline Engagement during Teaching Activities & Mean & SD \\
\hline Direct Instruction(DI) & 4.09 & 1.14 \\
Class Discussion(CD) & 3.45 & 1.13 \\
Small Group Work (SGW) & 4.64 & 0.50 \\
Cooperative Learning (CL) & 2.73 & 1.85 \\
Problem Solving (PS) & 2.18 & 1.72 \\
Student Research (SR) & 1.18 & 0.60 \\
Performance Activities (PA) & 3.55 & 1.44 \\
\hline
\end{tabular}


As shown above, the mean scores indicated that students were highly engaged during the teaching activities such as direct instruction, small group work, classroom discussion, and performance activities. The following illustrations provide examples of the activities that engaged students.

Students appeared to be very attentive when attending the course "Secondary ELT Methods: Developing Oracy Skills". Students in this lesson were asked to experience various activities after the lecturer introduced relevant classroom language skills for effective spoken interaction. Here are two examples in relation to direct instruction and small group work:

T'5 and Lesson' 9 (3:40-3:55pm): Good start to lesson by outlining the purposes of this class and using ppt slides to refer to key knowledge points of organizing stages for a speaking lesson. Students were interested and keen to learn. The lecturer involved all the students in his introduction. This part was delivered well with direct instruction successfully utilized. Students maintained their interests during the 10 minute direct teaching (Student engagement to DI scored 5).

T'5 and Lesson' 9 (3:55-4:08pm): The lecturer divided students into small groups to do the 1st speaking task on the topic of "Getting to know your group". Students were fully engaged in this activity by introducing each other's likes or dislikes. It was a helpful warm-up teaching exercise to arouse their interests (Student engagement to SGW scored 5).

Students appeared highly motivated in both classroom discussion and performance activities in the module "Advanced English Proficiency through the Media \& Developing Oracy". This module encouraged students to construct their own theories and pedagogies of L2 oracy development through dialogue, reflection and critical response. It provided students with an understanding of theory and pedagogical practice in oracy development (Department of English-HKIEd, 2009), as seen from the following notes:

T'2 and Lesson' 4 (4:40-4:48pm): The lecturer gave a general introduction by posting a question "Do you think storytelling can be helpful to children's language development? Why?" to draw students' attention. Students were very interested in this topic 'using storytelling for developing oracy'. They actively discussed what they thought (Student engagement to CD scored 5).

T'2 and Lesson' 4 (5:20-6:00pm): Students were asked to work in small groups to practise retelling the given stories "The Lilypad" or "Mousie's Adventures" and to present their group work to the class afterwards. Each group member needed to take a part. The students were listening carefully while the presenters were retelling their parts of stories. They all enjoyed this activity very much (Student engagement to PA scored 5).

Table 2 shows that the majority of students seemed to involve in their learning when their lecturers or tutors used the first three teaching activities or strategies direct instruction, classroom discussion and small group work.

\subsection{Classroom Interaction Including Teacher-Student and Peer-Peer Interactions}

Table 3 represented the records on classroom interaction including teacher-student and peer-peer interactions. The mean scores were estimated on the basis of five-point rating scale from 1 (never) to 5 (very often). The ten specific items which described the general information about communication situations were as follows: 
Table 3. Means and Standard Deviations of Classroom Interaction Data

\begin{tabular}{|c|c|c|}
\hline Items & Mean & SD \\
\hline $\begin{array}{l}\text { I: The teacher encouraged students to actively participate in the } \\
\text { classroom activities. }\end{array}$ & 4.00 & 0.45 \\
\hline $\begin{array}{l}\text { II: The teacher used students' multicultural backgrounds in organizing } \\
\text { activities. }\end{array}$ & 2.18 & 0.60 \\
\hline $\begin{array}{l}\text { III: The teacher worked as a resource person supporting and enhancing } \\
\text { students' investigation. }\end{array}$ & 2.64 & 0.81 \\
\hline $\begin{array}{l}\text { IV: The teacher worked as a facilitator scaffolding students and } \\
\text { promoting classroom interaction. }\end{array}$ & 3.73 & 0.65 \\
\hline $\begin{array}{l}\text { V: In general, the teacher-student interactions appeared cohesive and } \\
\text { productive. }\end{array}$ & 3.64 & 0.50 \\
\hline $\begin{array}{l}\text { VI: Students were involved in the communication of sharing ideas with } \\
\text { each other when working together. }\end{array}$ & 3.64 & 0.67 \\
\hline $\begin{array}{l}\text { VII: It appeared that most students preferred to work in neighboring } \\
\text { groups rather than being assigned by the teacher. }\end{array}$ & 3.45 & 0.93 \\
\hline $\begin{array}{l}\text { VIII: There was less interaction among students who were assigned to } \\
\text { be in mixed groups that comprised local Hong Kong students and } \\
\text { Mainland Chinese students. }\end{array}$ & 2.55 & 0.82 \\
\hline $\begin{array}{l}\text { IX: Different dialects used by Hong Kong students and Mainland } \\
\text { students affected their interaction during group discussion. }\end{array}$ & 2.27 & 0.90 \\
\hline $\begin{array}{l}\text { X: In general, there was a high proportion of student talk and positive } \\
\text { interaction among students. }\end{array}$ & 2.64 & 1.03 \\
\hline
\end{tabular}

The first three high mean scores were Item I (4.00), Item IV (3.73) and Item V (3.64). Teachers' stimulating activities and students' active participation led to a positive teacher-student interaction in general. Notes on the module "Adolescent Literature in the ESL Classroom" support this finding:

T'3 and Lesson' 6 (10:30-11:30am): ... There were also well-spaced and informative tasks for students to complete during the lecture which maintained student engagement impressively (Item I \& IV scored 4).

(10:35-10:55am): To make sure students stayed on the right track, she walked around to monitor the progress and to give positive comments. She also provided guidance and assistance to the students. Mutual respect between the teacher and the students was observed (Item V scored 4).

Students appeared to like forming neighboring groups comprised familiar students to achieve pleasant student-student communication. Such grouping behavior could be seen in the notes of "Primary ELT Curriculum". This module examined the principal components for planning a primary ELT curriculum in accordance with a task-based approach. It provided students with opportunities to gain insights into the development of teaching plans and become competent in developing English enrichment programs for primary pupils (Department of English-HKIEd, 2009). The lecturer often enabled students to participant in teaching activities in small groups to experience different ways of school-based curriculum design:

T'4 and Lesson' 7 (3:00-3:35pm): Students were asked to complete Task 1 in the handouts in groups by analyzing objectives for coherent language teaching. There were 23 students (9 local HK+14 MC). Students who were familiar with each other would sit together before the lesson started. 6 neighboring groups were formed by themselves depending on prior acquaintance (2 were host groups, 3 were MC groups and 1 was a mixed group). Most of them appeared to actively engage in group discussion and stayed on the required tasks (Item VII scored 4).

Item VIII (2.55) and Item X (2.64) got relatively lower scores across the ten items. This indicated that when unfamiliar students worked in a mixed group, most of them appeared to be reluctant to interact. An example from observation of the "Primary ELT Curriculum" supported this:

T'4 and Lesson' 7 (3:00-3:35pm): It was noted that when the MC students met unfamiliar HK student in a group, they seemed to have less communication than the other 5 groups because the students would sometimes switch their mother tongue (a colloquial Chinese-shanghai dialect and Cantonese) for clearer explanation so that this mixed groups of students sometimes seemed to be unwilling to join in their discussion (Item VIII scored 3 \& Item X scored 2). 
This example also showed use of different dialects or linguistic difference between students may inevitably affect their communication.

Item II (2.18) that examined cultural awareness of a diverse student body was weak despite the fact that there were cases in which teachers acknowledged cultural differences of their students:

T'1 and Lesson' 1 (11:30-11:40am): The lecturer introduced students to the researcher before class (9 HK students, $8 \mathrm{MC}$ exchange students studying for Module II and 2 Korean exchange students for Module 1). This was the first time that the teacher had precisely identified her students'different cultural backgrounds because she used to misrecognize the MC students as Koreans (Item II scored 2).

T'5 and Lesson' 9 (3:55-5:12pm): There were 20 students (6 local HK+14 MC+1 Canadian student) in this lesson. 5 groups were formed by the lecturer. Of these 5 groups, 3 were MC groups and 2 were mixed groups (One comprised of $2 \mathrm{HK}$ and 1 Canadian. The other involved $3 \mathrm{HK}$ and $3 \mathrm{MC}$ ). (5:12-5:28pm):The lecturer re-grouped students into 4 big groups to do Task 4: 'For \& against'. Again, different mixed groups were formed. Students with multicultural backgrounds were encouraged to work together (Item II scored 4).

Overall, the higher figures above led us to see a generally good teacher-student communication. Whereas, the less high mean scores showed that peer (Hong Kong students) to peer (Mainland Chinese students) interaction turned out to be weak. However, the majority of students preferred to form neighboring groups with their familiar counterparts in activities. Although teachers' awareness of cultural identity was estimated the lowest, the given examples demonstrated that two teacher was more conscious of noticing their students' multicultural backgrounds and putting them together to study.

\section{Discussion}

The study results have revealed several factors. One was that teacher-student interaction in class was generally positive although some teachers saw the students as one homogeneous body rather than two cultural cohorts. The other was that it confirmed the finding by Lam (2006) who reported that the interaction between Hong Kong and Mainland students was problematic. As Figure 1 shows:

\section{Teacher}

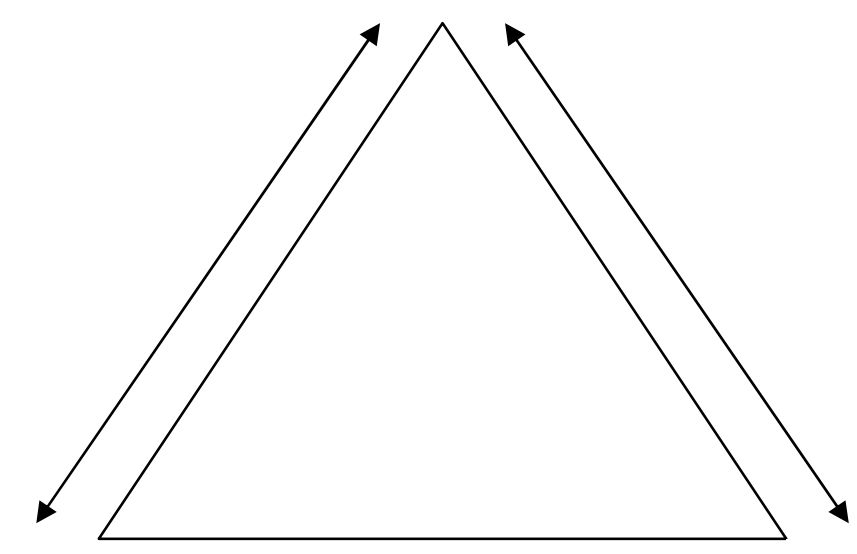

HK Student

\section{Student}

Figure 1. Classroom Interaction

This study has also found that linguistic difference and cultural background were the main factor affecting student interaction. Both Hong Kong and Mainland students appeared not to voluntarily work in a mixed group unless required by their teachers. They usually formed a neighbouring group that comprised friends or familiar classmates. This phenomenon could be explained by a principle of homophily which "structures network ties of every type including friendship, work, support...and other types of relationships" (McPherson et al., 2001, p.415). The effect of the principle is that "people's personal networks are homogeneous with regard to many sociodemographic, behavioural and intrapersonal characteristics" (McPherson et al., 2001, p.415). Homophily in 
social networks promotes more contact between people with similar ethnical, cultural and educational backgrounds than with those who are different from them. Students only concentrated on small social groups in which they had close ties between members. It occurred in the classroom setting of the study and it was common to see that students were more inclined to interact with those like themselves. This tendency, unfortunately, did not draw their teachers' sufficient attention when they engaged students in various teaching classes.

This homophily principle in student relationships are evidence to ascertain that Hong Kong and Mainland Chinese students cannot be generalised as a homogenous group. Different historical, social, cultural and educational backgrounds have made the two groups of students different from each other regardless that both groups of students are rooted in the Confucian heritage culture. However, it is argued that this phenomenon limits students' social worlds in the way that they get information, form a certain attitude, and experience interaction. The less interaction they had in class, the more social distance existed. Teachers need to be more aware of their learner behaviours and attitudes to learning and interaction so that they can consider modifying teaching practices to increase classroom interactions.

Most teachers showed an enthusiasm to apply different kinds of teaching strategies to ensure an effective transmission of subject knowledge. However, they seemed less concerned with student interaction, especially the peer to peer interaction of the two groups of students. One reason behind seemed to be relevant to teachers' willingness to teach culturally diversified students. The rapid change of student composition made them think about new ways of coping with the situation that they had never experienced before; the other might be that the problems in classroom interaction were unavoidable in the eyes of teachers because the two groups of students differed both linguistically and culturally. This view was demonstrated by a few approached teachers who stated that they could do nothing to change the situation or promote their interaction. However, classroom interaction in such a multicultural teaching and learning environment should consist not only of effective teacher-student interaction but also effective peer to peer interaction.

Nevertheless, studies have identified that large classes and heavy curriculum content seemed to discourage academic staff from prioritizing peer interaction from the pedagogic perspective, so a planned and intentional fostering interaction is limited available (Arkoudiset al., 2010). Therefore, a potential obstacle to peer interaction is most likely to be caused on teaching side. Literature suggests effective teaching strategies enhance peer connections in the classroom, increase rapport and promote adjustment (Processer \& Trigwell, 2006; Westwood, 2008). It was noted that a combination of two or three teaching strategies was a common practice in this study. Integration of English teaching strategies such as group work, cooperative learning and problem solving was well handled by teachers and was well received by most students. In the process of promoting peer interaction, teachers should prioritise the interactional features of strategies that encourage social interaction through working together. Particularly in a multilingual and multicultural classroom in Hong Kong, for example, group strategies can provide opportunities for diverse learners to learn how to cooperate and construct knowledge together and how to tolerant cultural difference and accept divergent opinions (Brady, 2006). Therefore, teachers should purposefully take advantage of group strategies to enhance and sustain student interaction. In the case of the higher education in any countries, the group activities should include both local and non-local students in the process of learning.

Group work, no matter how large or small, is a desired strategy in higher education because university highly values "the development of teamwork and interpersonal skills" (Grajczonek, 2009, p. 105). Grouping students to work together to establish a sense of common identity is helpful for teaching diverse learners. The more students communicate, the less misconception they have. It not only increases students' proactive engagement and develops independence, but also encourages social interactive skills and enhances communication (Westwood, 2008). By constructing knowledge interactively, students are able to learn from peers and benefit from the help of the more capable students through scaffolding. A purposeful selection and preparation of group work is necessary to achieve educational and social outcome. To promote students to interact, teachers must be culturally sensitive to get to know their diverse student body and learning styles. After that, teachers should mix students up in groups because mandatory group work offers opportunities for them to talk and enhance their rapport. Consciously mixing diverse students to assign groups tasks or group projects should be helpful for positive interaction. The mandatory mixed grouping could be managed randomly in a non-face-threatening manner, e.g., assigning a number (of 1,2 and 3...10) to each student, and let all students with the same number get together in groups. When the homophily principle limits their interactional pattern with dominant classmates, mandatory mixed groups help lessen such a negative effect and enhance peer interactions within the curriculum by a systematic plan. It should contribute to broadening the connection among students and providing students with mixed styles of learning perspectives. 


\section{Conclusion}

In summary, this study has captured several aspects of learning and teaching in the social cultural context in Hong Kong. Firstly, this study was conducted in the current climate in which students from diverse cultural backgrounds (mostly Mainland Chinese) are seeking higher education in Hong Kong's universities. The study results generally showed that some teachers seemed to lack awareness of teaching multicultural students in their classes and the peer interaction between local and Mainland students appeared weaker than non-mixed groups. The research findings are significant to higher education in Hong Kong and Mainland China since the findings are providing an understanding of interaction problems and how to use group strategies for the enhancement of classroom interaction among diverse learners. Only a few strategies that can facilitate to include student interaction have been discussed, but how to systematically construct a set of inclusive strategies other than group strategies to effectively enhance and sustain peer interaction in multicultural classrooms should be further explored and discussed.

Secondly, this study was a single case study because of time and space limitations. Ideally, more universities in Hong Kong could be investigated and more subjects could be included to generate more significant evidence and arguments in future research. For example, methodologically speaking, quantitative survey and qualitative interviews can be used to obtain more empirical research findings. Despite the limitation, the study results should not only make recommendations for curriculum design and teaching practices, but also have a potential impact on quality learning and teaching in universities other than those in Hong Kong in the context of internationlisation.

\section{References}

Arkoudis, S., Yu, X., Baik, C., Borland, H., Chang, S., Lang, I., Lang, J., Pearce, A., \& Watty, K. (2010). Finding common ground: Enhancing interaction between domestic and international students. Australian Learning and Teaching Council.

Brady, L. (2006). Collaborative learning in action. French Forest, N.S.W.: Pearson, Prentice Hall.

Creswell, J. W., \& Plano Clark, V. L. (2007). Designing and conducting mixed methods research. Thousand Oaks, Calif.: Sage. http://dx.doi.org/10.1177/1558689806298644

Dahlin, B., \& Watkins, D. A. (2000). The role of repetition in the processes of memorising and understanding: A comparison of the views of German and Chinese secondary school students in Hong Kong. British Journal of Educational Psychology, 70, 65-84. http://dx.doi.org/10.1348/000709900157976

Department of English-HKIEd. (2009). Undergraduate programs: Developing oracy. Retrieved from http://www.ied.edu.hk/curriculum/module/ENG2035.html

Department of English-HKIEd. (2009). Undergraduate programs: Primary ELT curriculum. Retrieved from http://www.ied.edu.hk/curriculum/module/ENG2259.html

Gao, X. (2007b). Language learning experiences and learning strategy research: Voiceso $f$ a mainland Chinese student in Hong Kong. Innovations in Language Learning and Teaching, 1(2), 193-207. http://dx.doi.org/10.2167/illt011.0

Grajczonek, J. (2009). Exploring students' perceptions of peer assessment in group work for allocation of individual marks in higher education. The International Journal of Learning, 16(3), 105-125.

Hsieh, H. (2012). Challenges facing Chinese academic staff in a UK university in terms of language, relationships and culture. Teaching in Higher Education, 17(4), 371-383. http://dx.doi.org/10.1080/13562517.2011.641001

Kember, D. (2001). Beliefs about knowledge and the process of teaching and learning as a factor in adjusting to study. Higher Education, 26(2), 205-21.

Killen, R. (2007). Effective teaching strategies: Lessons from research and practice (4th ed.). South Melbourne, Vic.: Thomson Social Science Press.

Kumaravadivelu, B. (2005). Understanding language teaching: From method to postmethod. Mahwah, NJ: Lawrence Erlbaum Associates, Inc.

Lam, M. H. (2006). Reciprocal adjustment by host and sojourning groups: Mainland Chinese students in Hong Kong. In M. Byram \& A. W. Feng (Eds.), Living and studying aboard: Research and Practice (pp. 91-108). Clevedon: Multilingual Matters.

Li, M., \& Bray, M. (2007). Cross-border flows of students for higher education: Push-pull factors and 
motivations of mainland Chinese students in Hong Kong and Macau. Higher Education, 53, 791-818. http://dx.doi.org/10.1007/s10734-005-5423-3

McPherson, M., Smith-Lovin, L., \& Cook, J. M. (2001). Birds of a feather: Homophily in social networks. Annual Review of Sociology, 27, 415-444. http://dx.doi.org/10.1146/annurev.soc.27.1.415

Prosser, M., \& Trigwell, K. (2006). Confirmatory factor analysis of the 'Approaches to teaching inventory'. British Journal of Educational Psychology, 76(2), 405-419. http://dx.doi.org/10.1348/000709905X43571

Richards, J. C., \& Rodgers, T. S. (2001). Approaches and methods in language teaching (2nd ed.). Cambridge: Cambridge University Press. http://dx.doi.org/10.1017/CBO9780511667305

Sit, H. W., \& Chen, S. (2010). The teaching strategies used for advanced English studies in English language teacher education. The International Journal of Learning, 17(6), 485-500.

Snider, P. D. (2005, 6th-9th July). Better meeting the counselling needs of ethnic Chinese international students: Exploring the relationship between cultural backgrounds and counselling expectations. Paper presented at the higher education in a changing world, Sydney.

$\mathrm{Su}$, S. J. (2006). Give me wings to fly-What can be done better to smooth Chinese students' academic adaptation experience at one Australian university?. In R. Giddings (Ed.), 17th International Education Conference Sydney 06. Australia: International Education Association Inc (ISANA). Retrieved from http://www.proceedings.com.au/isana/docs/2006/Paper_su.pdf

Thao, L., \& Li, S. (2006, 27 Novmember-1 December). Chinese-background Students' Learning Approaches. Paper presented at the AARE Annual conference, Adelaide.

The international students guide. (2010). International students in Australia. Retrieved from http://www.studiesinaustralia.com/studying-in-australia/why-study-in-australia/international-students-in-aus tralia

Trigwell, K., \& Shale, S. (2004). Student learning and the scholarship of university teaching. Studies in Higher Education, 29(4), 523-536. http://dx.doi.org/10.1080/0307507042000236407

University Grants Committee (UGC). (2010). Figures: Non-local Student Enrolment (Headcount) of UGC-funded programmes by institution, level of study, place of origin and mode of study, 2010/11.

Watkins, D. A., \& Biggs, J. B. (Eds.). (2001). Teaching the Chinese learner: Psychological and pedagogical perspectives. Hong Kong/Melbourne: CERC \& ACER.

Westwood, P. (2008). What teachers need to know about teaching methods. Camberwell, Vic.: ACER Press.

Zeng, M. (2006). The adaptation of Mainland Chinese research postgraduates to the University of Hong Kong (Unpublished doctoral dissertation). The University of Hong Kong, Hong Kong.

Zhang, Q. J. (2005). It's more than a piece of paper: Chinese students' experience of learning in Australia (Unpublished doctoral dissertation). Darwin University, NT, Australia. 